\title{
Hepatitis C infection in Egypt: prevalence, impact and management strategies
}

\section{Asmaa Gomaa' \\ Naglaa Allam' \\ Aisha Elsharkway ${ }^{2}$ \\ Mohamed El Kassas ${ }^{3}$ \\ Imam Waked'}

'Hepatology Department, National Liver Institute, Shebeen EL Kom, ${ }^{2}$ Endemic Medicine Department, Faculty of Medicine, Cairo University, ${ }^{3}$ Endemic Medicine Department, Faculty of Medicine, Helwan University, Cairo, Egypt

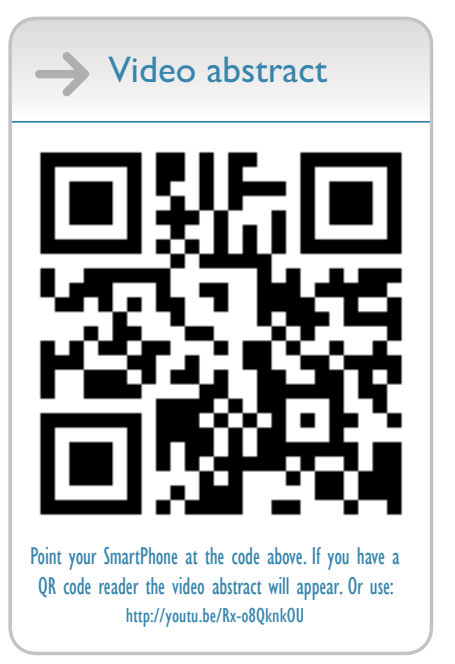

Correspondence: Imam Waked Hepatology Department, National Liver Institute, 108 Tahrir street, Dokki, Giza, Shebeen EL Kom I 23 I I, Egypt

$\mathrm{Tel}+20233368090$

Fax +20482234586

Email iwaked@liver-eg.org
This article was published in the following Dove Press journal:

Hepatic Medicine: Evidence and Research

15 May 2017

Number of times this article has been viewed

Abstract: Hepatitis C virus (HCV) infection is a major public health burden in Egypt, where it bears the highest prevalence rate in the world. Estimates for prevalence are based upon data reported from the 2008 and 2015 Egypt Demographic Health Surveys. In this review, we demonstrate the prevalence results of both surveys and analyze the difference in the results. The overall $\mathrm{HCV}$ prevalence is estimated to be declining. However, the clinical impact of chronic HCV infection is expected to grow considerably. A mathematical model shows that by increasing the rate of treatment, the expected number of patients will decline significantly in 2030 . The current and expected future burden of chronic HCV infection to the Egyptian economy, including direct and indirect costs due to disability and loss of lives, has been estimated and discussed in this review. The economic burden will continue to grow, but a model shows that the introduction of highly effective therapies will result in a significant reduction in the cumulative total economic burden of HCV by 2030. In recognition of the HCV tremendous health and economic burden, the Egyptian government established the National Committee for Control of Viral Hepatitis to implement an integrated nationwide strategy to provide patient care and ensure global treatment access. This review illustrates the epidemiological and disease burden aspects of HCV in Egypt in addition to introducing the national plan and program for managing $\mathrm{HCV}$, which has been successful so far in treating a large number of patients, with the aim of achieving disease control and eventual elimination in Egypt.

Keywords: hepatitis C in Egypt, prevalence, HCV burden, treatment strategy

\section{Prevalence}

The prevalence of hepatitis $\mathrm{C}$ virus (HCV) infection in Egypt is the highest in the world. ${ }^{1}$ This became apparent early on, soon after the discovery of HCV. Seroprevalence among Egyptian blood donors in the Kingdom of Saudi Arabia was found to be much higher than that in blood donors from all other nationalities. ${ }^{2}$ Since then, it became apparent that HCV infection was widespread among Egyptians and that it was the main cause of liver disease in the country. Until the HCV epidemic became apparent, schistosomiasis was the most important public health problem in Egypt. ${ }^{3}$ In 1918, Christopherson made the discovery that injections with the antimony salt, tartar emetic, could induce a cure. ${ }^{4}$ Mass treatment of the parasite was then introduced, and from the 1950 s to the 1980 s, nationwide mass anti-schistosomal therapy with a series of intravenous injections of tartar emetic was adopted by the Egyptian Ministry of Health (MOH) with the advice and support of the World Health Organization (WHO)., ${ }^{5,6}$ More than 2 million injections were given annually to an average of 250,000 patients. Over the 18 years of treatment, 36 million injections were administered to $>6$ million 
people, almost all with unsterilized and shared syringes and needles. This represents the largest ever iatrogenic spread of blood-borne infection. ${ }^{6}$

Several national studies over time showed very high seroprevalence, ${ }^{7-10}$ and a large study in the Nile Delta in 1996 found a seroprevalence of $24 \%$ and viremic prevalence of $15 \%$ among 3,999 examined adults and children, with seroprevalence in adults $>40 \% .^{11}$

The Demographic Health Survey (DHS) of $2008^{12}$ showed a national seroprevalence of $14.7 \%$ among those aged between 15 and 59 years, with viremic prevalence of $9.7 \%$ in this age group that increased with age and was higher in males than in females in all age groups studied (Figure 1).

In a modeling study, to estimate the prevalence in those aged $<15$ years in 2008, an exponential decline in viremic prevalence was trended, and prevalence in those aged $>59$ years was set by the authors to be equal to that in those aged 59 years. Using this model, it was estimated that the national seroprevalence in 2008 was $12.5 \%$ and the viremic prevalence was $8.5 \%$, and that 6.3 (5.7-7.0) million people were living with HCV infection. ${ }^{13}$

A mathematical model was used to estimate the 2014 prevalence. Assuming that 65,000 patients were treated annually with pegylated (PEG) interferon and ribavirin (RBV)
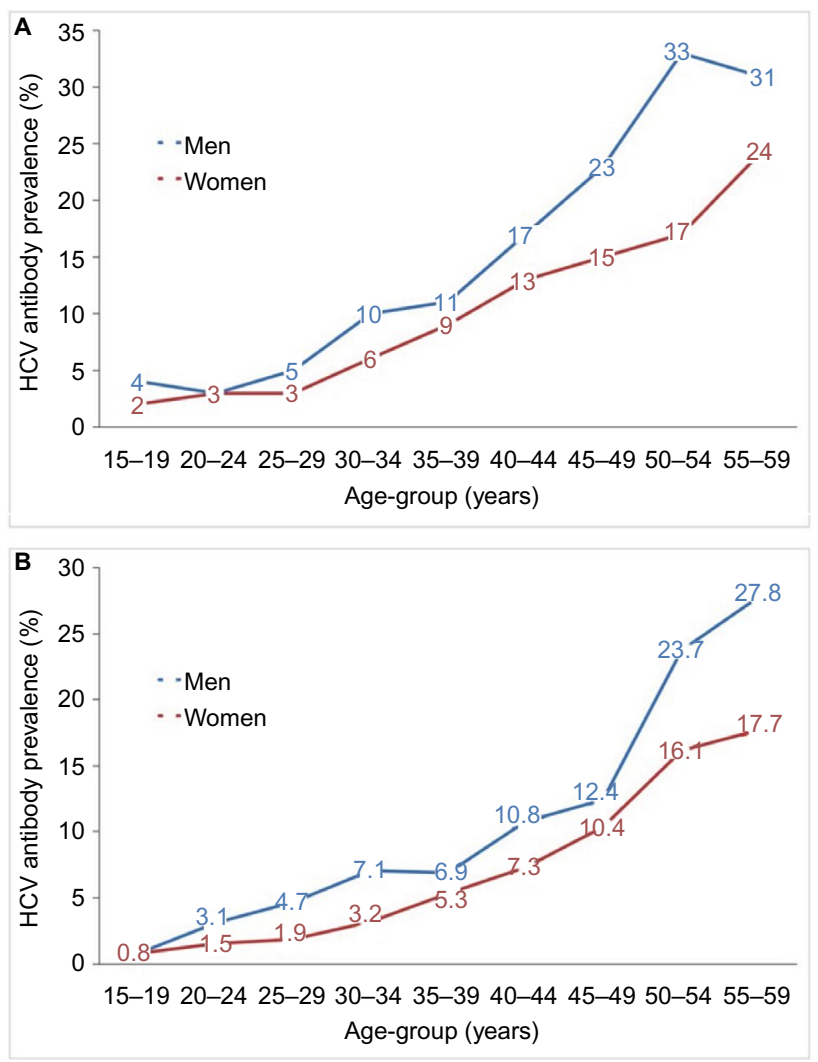

Figure I Percent of men and women with hepatitis $C$ antibody by age in Egypt in (A) $2008^{12}$ and (B) 2015..$^{15}$

Abbreviation: $\mathrm{HCV}$, hepatitis $\mathrm{C}$ virus. with a sustained virologic response (SVR) rate of $\sim 50 \%$, that 32,000 patients were cured, that an estimated 150,000 new infections occur annually leading to 100,000 chronic HCV infections and that 150,000 persons with HCV die $(120,000$ of causes other than liver disease and 30,000 of HCV-related complications), seroprevalence was modeled to $10.6 \%$ and viremic prevalence to $7.3 \%$ in $2014 . .^{13,14}$

\section{Decreasing prevalence}

The DHS of $2015^{15}$ included the age groups 1-59 years. The seroprevalence in the age groups $15-59$ years was $10 \%$ (compared to $14.7 \%$ in the 2008 DHS), and the prevalence in the group aged $<15$ years was $0.4 \%$, which brought the total seroprevalence in those aged $<60$ years to $6.3 \%$ and the viremic prevalence to $4.4 \%$ ( $7 \%$ in the age groups $15-59$ years and $0.2 \%$ in those aged $<15$ years).

Kandeel et $\mathrm{al}^{16}$ analyzed the prevalence data in the 2015 DHS and concluded that the significantly lower prevalence in those aged 15-19 years compared to the 2008 data points to a significant decrease in new infections in the age groups that were not represented in the previous DHS. They also highlighted the fact that the lower prevalence in the 2015 DHS is partly attributed to the aging of the group with the highest prevalence and their shift outside the age range of 1-59 years in the 2015 DHS. These were the age groups with the highest prevalence in the 2008 study and who mainly received anti-schistosomal injections in the 1950s and 1960s.

\section{Still ongoing transmission}

Although it appears to indicate that HCV infection is going away, however, this is not totally true. Table 1 shows the total national data in the 2008 DHS with modeling of the prevalence in the age groups $<15$ years and keeping the prevalence in those aged $>59$ years equal to that in those 55-59 years old and the 2015 DHS data for the whole population with keeping the prevalence in those aged $>59$ years equal to the prevalence in those aged 55-59 years in the 2008 DHS. If those aged $>59$ years are added to the 2015 DHS data, the viremic prevalence in the total population would be $6.2 \%$, and a total number of 5,600,000 patients would be living with HCV infection in Egypt in 2016 compared to 5,825,000 in 2008. Although viremic infections in those aged $<25$ years decreased from 805,000 to 300,000 cases (a reduction of 505,000 cases), the total prevalence in the population decreased by 325,000 cases only. This points to an ongoing infection in the older age groups.

By 2015, the age groups 15-45 years in the 2008 DHS have aged 7 years and moved to the groups aged 10 years 
Table I Age-specific HCV antibody and RNA prevalence in Egypt in 2008 and 2015

\begin{tabular}{|c|c|c|c|c|c|c|c|c|}
\hline $\begin{array}{l}\text { Age group } \\
\text { (years) }\end{array}$ & $\begin{array}{l}2008 \\
\text { Population }^{47}\end{array}$ & $\begin{array}{l}\text { HCV Ab, } \\
\%\end{array}$ & $\begin{array}{l}\text { HCV RNA, } \\
\%\end{array}$ & $\begin{array}{l}\text { HCV RNA, } \\
n\end{array}$ & $\begin{array}{l}2015 \\
\text { Population }^{48}\end{array}$ & HCV Ab, \% & $\begin{array}{l}\text { HCV RNA, } \\
\%\end{array}$ & HCV RNA, n \\
\hline$<5$ & $7,718,920$ & 2. $1^{\mathrm{a}}$ & $1.0^{\mathrm{a}}$ & 74,133 & $10,073,000$ & 0.4 & 0.2 & 20,146 \\
\hline $5-9$ & $7,644,227$ & $2.6^{\mathrm{a}}$ & $1.4^{\mathrm{a}}$ & 104,879 & $9,352,000$ & 0.3 & 0.25 & 23,380 \\
\hline $10-14$ & $7,718,49$ & $3.3^{\mathrm{a}}$ & $2.0^{\mathrm{a}}$ & 151,282 & $8,386,000$ & 0.7 & 0.3 & 25,158 \\
\hline $15-19$ & $8,539,832$ & 4.1 & 2.8 & 239,115 & $8,597,000$ & 1.0 & 0.8 & 68,776 \\
\hline $20-24$ & $7,873,192$ & 4.9 & 3.0 & 236,196 & $9,150,000$ & 3.2 & 2.2 & 201,300 \\
\hline $25-29$ & $6,391,623$ & 6.1 & 3.9 & 249,273 & $8,606,000$ & 4.4 & 3.0 & 258,180 \\
\hline $30-34$ & $4,733,495$ & 11.8 & 8.3 & 392,880 & $6,898,000$ & 7.1 & 4.9 & 338,002 \\
\hline $35-39$ & $4,656,897$ & 13.8 & 9.9 & 461,033 & $5,4 \mid 2,000$ & 8.2 & 6.0 & 324,720 \\
\hline $40-44$ & $4,092,499$ & 23.0 & 15.0 & 613,875 & $4,857,000$ & 11.6 & 9.0 & 437,130 \\
\hline $45-49$ & $3,674,382$ & 28.6 & 18.9 & 694,458 & $4,458,000$ & 16.3 & 11.3 & 503,754 \\
\hline $50-54$ & $3,061,286$ & 38.3 & 25.3 & 774,505 & $3,870,000$ & 27.9 & 19.9 & 770,130 \\
\hline $55-59$ & $2,265,429$ & 39.4 & 27.4 & 620,728 & $3,161,000$ & 33.9 & 22.1 & 698,581 \\
\hline $60-64$ & $\mathrm{I}, 705,502$ & $39.4^{b}$ & $27.4^{b}$ & $467,308^{b}$ & $2,317,000$ & $39.4^{c}$ & $27.4^{c}$ & $634,858^{c}$ \\
\hline $65-69$ & $1,193,600$ & $39.4^{b}$ & $27.4^{b}$ & $327,046^{b}$ & $1,630,000$ & $39.4^{c}$ & $27.4^{c}$ & $446,620^{\circ}$ \\
\hline 70-74 & 789,892 & $39.4^{\mathrm{b}}$ & $27.4^{\mathrm{b}}$ & $216,430^{b}$ & $1,075,000$ & $39.4^{c}$ & $27.4^{c}$ & $294,550^{c}$ \\
\hline$>75$ & 738,764 & $39.4^{b}$ & $27.4^{\mathrm{b}}$ & $202,42 I^{b}$ & $\mathrm{I}, \mathrm{I} 20,000$ & $39.4^{c}$ & $27.4^{c}$ & $306,880^{c}$ \\
\hline Total & $72,798,031$ & $12.0 \mathrm{I}^{\mathrm{b}}$ & $8^{b}$ & $5,825,563^{b}$ & $88,962,000$ & $8.6^{c}$ & $6^{c}$ & $5,352,165^{c}$ \\
\hline
\end{tabular}

Notes: aModeled data. 'Set equal to the age group 55-59 years. 'Set equal to the age group 55-59 years in 2008. Data from. ${ }^{12-15}$

Abbreviations: $\mathrm{HCV}$, hepatitis $\mathrm{C}$ virus; $\mathrm{Ab}$, antibody.

Table 2 HCV viremic prevalence in 2008 and 2015 in adults aged I5-50 years in 2008

\begin{tabular}{|c|c|c|c|c|c|c|}
\hline \multicolumn{3}{|l|}{2008} & \multicolumn{3}{|l|}{2015} & \multirow[t]{2}{*}{ Difference } \\
\hline Age group (years) & HCV RNA, \% & HCV RNA, n & Age group (years) & HCV RNA, \% & HCV RNA, n & \\
\hline $15-19$ & 2.8 & 239,115 & $25-29$ & 3.0 & 258,180 & 19,065 \\
\hline $20-24$ & 3.0 & 236,196 & $30-34$ & 4.9 & 338,002 & 101,806 \\
\hline $25-29$ & 3.9 & 249,273 & $35-39$ & 6.0 & 324,720 & 75,447 \\
\hline $30-34$ & 8.3 & 392,880 & $40-44$ & 9.0 & 437,130 & 44,250 \\
\hline $35-39$ & 9.9 & 461,033 & $45-49$ & 11.3 & 503,754 & 42,681 \\
\hline $40-44$ & 15.0 & 613,875 & $50-54$ & 19.9 & 770,130 & 156,255 \\
\hline $45-49$ & 18.9 & 694,458 & $55-59$ & 22.1 & 698,581 & 4,123 \\
\hline
\end{tabular}

Note: Data from El-Zanaty et al and Ministry of Health. ${ }^{12,15}$

Abbreviation: $\mathrm{HCV}$, hepatitis $\mathrm{C}$ virus.

in the 2015 DHS. The prevalence in these groups 7 years later has slightly increased, and the increase in prevalence in these age groups points to still ongoing transmission among the adult population. The increase in the number of HCVinfected patients in this age group (now aged 25-59 years) indicates an ongoing transmission in this age group at a rate of 1.4/1000 patient-years ( $95 \%$ confidence interval [ $95 \% \mathrm{CI}]$ : 1.1/1000-1.8/1000 patient-years) (Table 2).

The 2015 DHS included tests for anti- hepatitis B core antibody (anti-HB) and hepatitis B surface antigen (HBsAg) in addition to testing for HCV. The age prevalence of anti-HBc (indicating exposure to hepatitis $B$ virus $[\mathrm{HBV}]$ infection) mirrors the age prevalence of anti-HCV in both males and females (Figure 2), indicating parenteral exposure to both viruses and pointing out to ongoing iatrogenic exposure even in population who were not exposed to parenteral anti-schistosomal therapy (those aged $<40$ years).

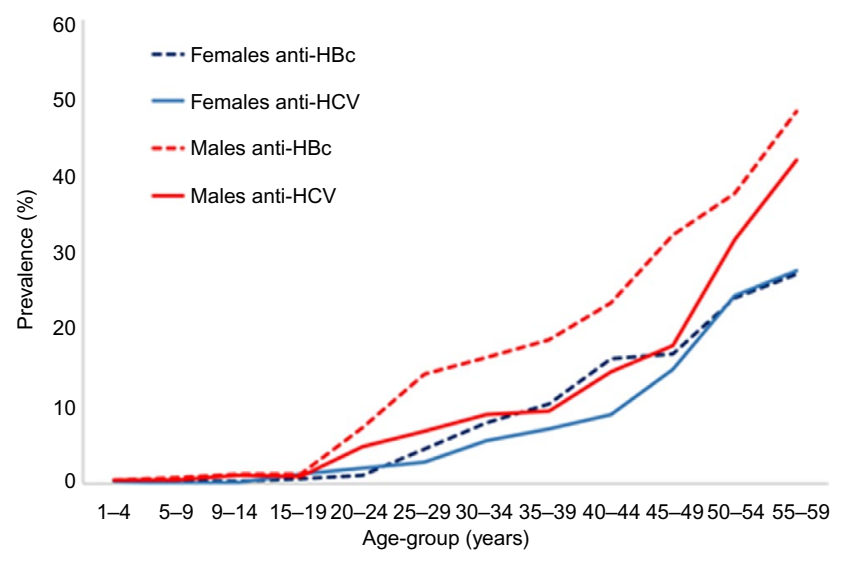

Figure 2 The age prevalence of anti-HBc and anti-HCV Abs in males and females. ${ }^{15}$ Abbreviations: HCV, hepatitis C virus; Abs, antibodies; $\mathrm{HBc}$, Hepatitis B core antibody.

\section{Impact of HCV infection}

Chronic infection with HCV is the leading cause of endstage liver disease, hepatocellular carcinoma (HCC) and liver-related death in Egypt. HCV causes chronic hepatitis 
in $60 \%-80 \%$ of the patients, and $10 \%-20 \%$ of those patients develop cirrhosis over 20-30 years of HCV infection. About $1 \%-5 \%$ of the patients with liver cirrhosis may develop liver cancer and 3\%-6\% may decompensate during the following 20-30 years. The risk of death in the following year after an episode of decompensation is between $15 \%$ and $20 \%{ }^{17}$

$\mathrm{HCV}$-associated disease is one of the leading causes of $\mathrm{HCC}$ and the main indications for liver transplantation. ${ }^{18}$ In Egypt, a systematic review including 13 studies on 2,386 patients estimated the annual rates of death/transplantation, decompensation and $\mathrm{HCC}$ in patients with compensated HCV cirrhosis to be $4.58 \%, 6.37 \%$ and $3.36 \%$, respectively. ${ }^{19}$ A single-center prospective study of 1,286 Egyptian patients with HCV cirrhosis estimated the annual incidence of $\mathrm{HCC}$ with $5.3 \%{ }^{20}$

In addition, $\mathrm{HCV}$ infection increases the risk of type 2 diabetes mellitus and is associated with a number of extrahepatic manifestations (arthralgia, cryoglobulinemia, skin manifestations, sicca syndrome and thyroid disorders $)^{21}$ and increases the risk for circulatory diseases, kidney diseases, renal failure, cancers of the esophagus, prostate and thyroid ${ }^{22}$ and all-cause mortality. ${ }^{23}$ Overall, $15 \%-35 \%$ of patients with chronic HCV have circulating cryoglobulins, and 5\%-25\% of them will develop clinical consequences including mixed essential cryoglobulinemia, systemic vasculitis, peripheral neuropathy and membranoproliferative glomerulonephritis. ${ }^{24}$

The incremental prevalence of diabetes attributable to HCV came from previously published literatures. ${ }^{25,26}$ There were an estimated 580,000 cases of HCV-attributable diabetes in 2013 (9.7\% of the viremic population). The risk of developing a non-Hodgkin's B-cell lymphoma is increased in patients with chronic $\mathrm{HCV}$, as a consequence of long-term B-cell stimulation. The age-standardized incidence rates of non-Hodgkin's lymphoma (NHL) in Egypt is 14.2/100,000, ${ }^{27}$ representing $\sim 12,500$ new cases annually. The proportion caused by HCV infection is $42 \%$ or an estimated 4,930 incident NHL cases annually. Achieving SVR reduces the incidence of lymphoma, decreases the risk of type 2 diabetes and its associated complications and improves patients' overall quality of life. ${ }^{28}$
Definitely $\mathrm{HCV}$ has a major impact on the quality of life. Individuals with $\mathrm{HCV}$ may experience chronic fatigue, depression, fibromyalgia and anxiety resulting in lower quality of life. $^{29}$

In Egypt in 2014, there were an estimated 125,000 viremic individuals being newly diagnosed each year: $10 \%$ of those with chronic hepatitis, $30 \%$ of those with compensated cirrhosis, while the majority ( $60 \%$ ) were diagnosed with decompensated cirrhosis or HCC. ${ }^{14,30}$ The number of patients in different disease stages, including chronic hepatitis (METAVIR stages F0-F3), compensated cirrhosis (F4), decompensated cirrhosis, HCC and liver transplant, is estimated in Table $3 .^{29}$

Despite this tremendous burden, most patients remain undiagnosed and therefore not appropriately managed. The number of patients needed to be treated annually to reach disease elimination by 2030 was calculated in a modeling study ${ }^{14,29}$ and was estimated to be 350,000 patients a year, with treatments that are $90 \%$ effective. To achieve this, the number of annually diagnosed new patients must exceed 350,000 a year. If this is coupled with a decrease in the incidence of new cases by $>20 \%$ annually, the burden of HCV-related disease in 2030 would decrease as shown in Table $3 .{ }^{14}$

Another study ${ }^{31}$ estimated the current and the future burden of HCV in Egypt by applying different treatment scenarios regarding treatment rate and treatment efficacy using Markov model to follow up HCV-infected cohort over time among different age groups using Egyptian DHS 2008 data. Patients with cirrhosis are expected to increase from 750,000 cases in 2015 to peak to 925,000 cases by 2022 and then slightly decrease to reach 800,000 cases by 2030 . By increasing the rate of treatment to $8 \%$ (treating 300,000-450,000 patients), the expected total viremic $\mathrm{HCV}$ cases will reach $1,000,000$ cases by 2030 , liver-related deaths will be $<15,000$ deaths and the number of patients with cirrhosis will decline by $87 \%$ to reach $\sim 100,000$ cases by 2030 .

\section{Economic burden}

The total burden of chronic HCV infection to the Egyptian economy, including direct costs (HCV-related health care

Table 3 Estimate of HCV disease burden in 2013 and 2030, in Egypt

\begin{tabular}{llll}
\hline & 2013 Estimate & 2030 Estimate & Change from 2013, \% \\
\hline Total number of infected individuals & $6,000,000$ & 280,000 & -95 \\
Number of compensated cirrhosis & 630,000 & 76,000 & -88 \\
Number of decompensated cirrhosis & 138,000 & 17,000 & -87 \\
Number of HCC & 16,000 & 2,400 & -85 \\
Number of HCV-related mortality & 33,000 & 7,500 & -77 \\
\hline
\end{tabular}

Note: Data from Razavi et al and Waked et al. ${ }^{13,14}$

Abbreviation: $\mathrm{HCV}$, hepatitis $\mathrm{C}$ virus. 
costs) and indirect costs due to disability (the value of lost productivity among chronically infected individuals) and due to loss of life, has been evaluated. ${ }^{30}$ Direct costs were calculated for $\mathrm{HCV}$-infected individuals who were diagnosed and under care. Indirect costs, years of life lost due to disability (YLD) and years of life lost due to premature death (YLL) were estimated using disability templates from the $\mathrm{WHO}^{32}$ and calculated to determine cumulative disability-adjusted life years (DALYs). This was used to calculate the total economic value of lost productivity using Egyptian estimates for the value of a statistical life year. ${ }^{30}$

The total economic burden of HCV in Egypt in 2015 was estimated at US\$3.81 billion, equivalent to $1.4 \%$ of total Gross Domestic Product (GDP), ${ }^{33}$ relatively as large as the cost of diabetes in the US. ${ }^{34}$ Direct health care costs of HCVrelated disease exceed $\$ 700$ million annually and consume $\sim 4.0 \%$ of the total health expenditure in Egypt, indicating that $\mathrm{HCV}$ and its related complications are a substantial health and economic burden. ${ }^{35}$

About $70 \%$ of the HCV prevalent population in 2015 was born between 1945 and 1975, and thus, the disease burden related to $\mathrm{HCV}$ and associated costs will continue to grow as the number of individuals experiencing advanced liver disease and HCC increases, although the overall HCV prevalence is declining. Indirect costs account for two-thirds of total costs associated with HCV in a US study. ${ }^{36}$ In Egypt, the estimated cumulative direct costs range from $26 \%$ (for historical treatment of PEG) to $33 \%$ (for recent treatment, despite the reduced cost of direct-acting antivirals [DAAs] and the availability of generic drugs) of total costs. ${ }^{30}$ Estimated indirect costs accounted for at least $80 \%$ of total costs for most disease stages, and estimated lifetime DALYs ranged from 5.7 for chronic hepatitis to 25.9 for HCC. Estimated YLLs ranged from 1.1 (chronic hepatitis) to 24.7 (HCC).

Despite the fact that $\mathrm{HCV}$ infection rates are decreasing, the clinical and economic impact of chronic HCV infection is expected to grow considerably. Infected population are expected to progress to more advanced stages of liver disease, despite the decline in the total number of infected individuals, and thus, a peak in cases of HCC, decompensated cirrhosis, liver-related deaths and compensated cirrhosis is expected. Older individuals were prone to have more advanced liver disease and associated liver-related deaths and higher allcause mortality rate. ${ }^{37}$

Estes et $\mathrm{a}^{30}$ evaluated the impact of adopting highly effective therapy for $\mathrm{HCV}$ and estimated the national economic burden of hepatitis $\mathrm{C}$ infection in 2015 and modeled future costs comparing to the historical case had DAAs not been adopted for HCV treatment by the national treatment program. Future disease progression was based on previously published work, ${ }^{37}$ and costs were projected from 2015 to 2030 based on historical therapy of PEG and RBV. The impact of changing treatment to the currently used DAAs with greater efficacy and the additive effect of increasing the treated population and reducing new infections were considered in terms of future economic burden and compared with the historical therapeutic regimen.

Table 4 shows the cumulative DALYs and direct, indirect and total costs between 2013 and 2030. Had DAAs not been used, the cumulative total economic burden of HCV disease between 2013 and 2030 was estimated at $\$ 89.1$ billion. The introduction of highly effective therapies with scaling-up of treatment to $>350,000$ patients a year will result in a significant decrease in DALYs, direct and indirect costs and a reduction in the cumulative total economic burden of $\mathrm{HCV}$ by $35.4 \%$ to $\$ 57.6$ billion. $^{30}$

The model by Shelbaya et $\mathrm{al}^{31}$ showed that the estimated cost of applying 1\% treatment rate will be $\$ 600$ million in 2015 and then decline to $\$ 500$ million by 2030 , where all viremic $\mathrm{HCV}$ cases will decline by $15 \%$ to reach $\sim 5.5$ million cases. Adopting 5\% treatment rate will decrease the cost from $\$ 900$ million in 2015 to $\$ 550$ million by 2030 as this policy will lead to decrease all viremic cases by $61 \%$ to reach 2.5 million cases. Applying 8\% treatment rate will increase the cost of treatment to $\$ 1.3$ billion in the first year of treatment and then decrease gradually to reach $\$ 580$ million by 2030 , leading to decrease in all viremia cases by $84.6 \%$ to reach 1 million cases by 2030 .

Mankoula developed a Markov model representing the progression among $\mathrm{HCV}$-infected cohort within different age

Table 4 Estimate of cumulative direct and indirect costs of HCV in different treatment scenarios between 2013 and 2030 in Egypt

\begin{tabular}{llll}
\hline & Base case & Increased efficacy and treatment & Percent change \\
\hline Cumulative DALY 20I3-2030 & $7,875,440$ & $4,923,210$ & $-37.5 \%$ \\
Cumulative direct costs 20I3-2030 (US\$) & $23,244,377,860$ & $18,632,607,710$ \\
Cumulative indirect costs 20I3-2030 (US\$) & $65,822,552,110$ & $38,929,874,750$ & $-19.8 \%$ \\
Cumulative total costs 20I3-2030 (US\$) & $89,066,929,970$ & $57,562,482,460$ \\
\hline
\end{tabular}

Note: Data from Estes et al. ${ }^{30}$

Abbreviations: HCV, hepatitis C virus; DALY, disability-adjusted life year. 
groups from 2015 till 2025. The burden of hepatitis C was estimated, and the direct and indirect health care cost of the proportion of members who go through each stage of the disease and its complications was calculated. Under the current management strategy of treating 125,000 patients/year with DAA, it is estimated that chronic active HCV patients will show minimal decrease to reach $\sim 4.1$ million cases, with $\$ 23.3$ billion estimated as a direct cost, and the total costs are $\$ 48.3$ billion between 2015 and 2025 . $^{38}$

Increasing the treatment rate to reach 1 million patients annually for 5 years in addition to decreasing the annual incidence in the coming 10 years will drop HCV cases to $\sim 636,000$ by 2025 , with the direct costs estimated to be only $\$ 16.2$ billion and total costs are estimated to be $\$ 34.2$ billion between 2015 and 2025, which is $29.2 \%$ lower than the current management scenario. ${ }^{38}$

\section{Treatment strategy and outcome}

The national treatment strategy for control of HCV infection in Egypt $^{39}$ was set by the National Committee for Control of Viral Hepatitis (NCCVH) which was established by the $\mathrm{MoH}$ in 2006, in response to the magnitude of the HCV problem and burden of disease in Egypt. ${ }^{40}$ This committee had an advisory board of volunteer hepatology and epidemiology professors and included international experts from Pasteur Institute, Paris, and the University of California, San Francisco.

The objectives of the NCCVH were assessment of HCV disease burden, establishing the infrastructure for a national treatment program and setting a national strategy for control of viral hepatitis that was first published in 2007. The primary policy was to provide antiviral medications to all patients at either reduced cost or totally free (on the expense of the state).

The role of NCCVH was to set action plans, issue treatment protocols and practice guidelines and establish and oversee the specialized viral hepatitis treatment centers. The committee also led negotiations with the pharmaceutical manufacturers to reduce the prices of antiviral medications for the treatment program.

The geographical distribution of treatment centers was planned so that any patient would be within $50 \mathrm{~km}$ to a nearby center. Treatment centers are operated through a well-trained team of specialized hepatologists and infectious disease specialists. Until 2017, >54 centers were established providing care to $>800,000$ chronic patients. A dedicated intranet network (the National Network for Treatment Centers [NNTC]) was established, and users in all centers were interconnected to a central database where baseline and follow-up patient data were recorded.
In 2014, negotiations between the NCCVH and Gilead Sciences, the US manufacturer of sofosbuvir (SOF) (Sovaldi ${ }^{\circledR}$ ), led to an agreement to provide the drug for Egyptian patients treated through the national program at the reduced price of $\$ 300$ per bottle (compared to $\$ 28,000$ per bottle in the US market). ${ }^{41}$ The deal with Gilead Sciences was the base for setting the cost of introducing other DAAs in Egypt. Similar negotiations with the other DAA manufacturers led to equivalent reduction of prices: simeprevir (SMV) (Janssen) and daclatasvir (DCV) (Bristol-Meyers-Squibb) at \$250, paretaprevir-ombitasvir (AbbVie) and SOF-ledipasvir (Gilead Sciences) for the equivalent of $\$ 300$. Local production of generic DAAs was encouraged, and the cost of treatment has reduced further.

With the introduction of genotype-4-effective DAAs to Egypt, the main problem was organizing and streamlining patient visits to the then available 26 specialized centers. The estimated number of patients who were waiting for new treatments was $>750,000: \sim 150,000$ patients who failed previous standard of care therapy with interferon (IFN) and RBV, $300,000-500,000$ patients who were estimated to have been "not fit" for IFN therapy, in addition to $\sim 150,000$ who were previously diagnosed and preferred not to be treated with IFN and to wait the new medications. This necessitated a novel administrative solution that was innovated for the first time in the health care setting in Egypt. A specially designed webbased online registration system (www.nccvh.org.eg) was created in order to register patients with $\mathrm{HCV}$ and schedule appointments for the first visit at the treatment centers. The centers' capacity set the daily workload and appointments, and patients were referred to the nearest treatment center to their residence.

With the first week after launching the site, $>300,000$ patients registered and received appointments online. This created a further problem, as the waiting times exceeded 6 months in some centers (according to the prevalence in the area and the capacity of the center). The management of this was through opening of more centers in the crowded areas to help ease the wait list, and by mid-2016, the wait time for the first appointment was reduced to within a week of registration in all centers.

The main source of funding for this program was through "the governmental support funds" directed to those who are not covered by health insurance. These funds cover treatment and all pre- and posttreatment investigation for $>90 \%$ of the patients.

Patients visit treatment centers monthly for clinical and laboratory follow-up and receive the monthly supply 
of medication, and an SVR is assessed at 12 weeks after the end of treatment. Patients with cirrhosis are offered ultrasonography and alpha fetoprotein every 6 months as surveillance for HCC.

To enhance patients' compliance with follow-up to assess SVR, a "certificate of cure from hepatitis C" was issued for patients who test negative for HCV RNA 12 weeks after the end of treatment.

The national goal of the HCV management program in Egypt was to reduce the prevalence $<2 \%$ within 10 years and to near elimination of the disease (prevalence $<1 \%$ ) by 2030. Modeling studies before the start of the DAA treatment program showed that Egypt needs to scale up treatment to 350,000 patients a year by medications that are associated with $>90 \%$ cure rate to achieve these ambitious goals. ${ }^{14,30,37}$ This scale up required governmental and societal commitments and further reduction in cost.

Initially, treatment priority was given to those with advanced fibrosis, and this was in line with most international recommendations. ${ }^{42,43}$ SOF, PEG and RBV were the only available medications initially, and with the availability of results of SOF-based therapy for HCV genotype 4 from clinical trials, ${ }^{44}$ treatment was initially provided for patients with F3 and F4 fibrosis. Although the SVR rates in patients who received SOF-RBV for 24 weeks was significantly lower than in those who received IFN in addition to SOF-RBV (76\% vs $90 \%)$, no other alternatives were available for IFN-ineligible patients for the first 6 months of the program.

SMV, which became available during the next 6 months, was used in combination with SOF for the treatment of $\sim 100,000$ patients. The guidelines were modified based on the results of a local clinical trial ${ }^{45}$ to include SOF-SMV for 12 weeks in patients with or without Child-Pugh A cirrhosis. When the results of SOF-RBV for 24 weeks were published, ${ }^{46}$ the regimen was replaced by SOF-SMV. This was followed by the availability of locally produced generic SOF in the following 6 months and generic DCV 3 months later. Accordingly, the national guidelines were modified to be exclusively IFN free, by giving SOF-DCV with or without RBV for 12 weeks to all patients. The main rationale behind this was cost, as the cost of the generic combination of SOF-DCV was $20 \%$ of the reduced cost of SOF-PEG-RBV or SOF-SMV. The reduction in prices continued and is now at US\$27 for a 4-week supply of generic SOF-DCV combination, which has been exclusively used for all patients in the program since early 2016. The high response rates with the locally produced generics support the use of low-cost generics in similar programs in limited resource settings.

Table 5 and Figure 3 show the results of SVR12 with the different treatments used in the national program.

Table 5 Outcome of therapy with different DAA regimens in Egypt in 2015-2016

\begin{tabular}{|c|c|c|c|c|c|}
\hline & $\begin{array}{l}\text { SOF-PEG-RBV } \\
\text { I } 2 \text { weeks }\end{array}$ & $\begin{array}{l}\text { SOF-RBV } \\
24 \text { weeks }\end{array}$ & $\begin{array}{l}\text { SOF-SMV } \\
\text { I } 2 \text { weeks }\end{array}$ & $\begin{array}{l}\text { SOF-DCV } \\
\text { I } 2 \text { weeks }\end{array}$ & $\begin{array}{l}\text { SOF-DCV-RBV } \\
\text { I } 2 \text { weeks }\end{array}$ \\
\hline Number & 13,260 & 7,958 & 6,160 & 10,120 & 8,258 \\
\hline SVRI2, n (\%) & I I,907 (90) & $6,040(76)$ & $5,739(93)$ & $9,653(95)$ & $7,820(95)$ \\
\hline Nonresponse, n (\%) & $904(7)$ & $934(12)$ & $292(5)$ & $359(3.5)$ & 349 (4) \\
\hline Relapse, n (\%) & $450(3)$ & $984(12)$ & $129(2)$ & $108(1)$ & $89(1)$ \\
\hline
\end{tabular}

Note: El Raziky et al and Doss et al. ${ }^{45,46}$

Abbreviations: DAA, direct-acting antivirals; SOF, sofosbuvir; PEG, pegylated interferon; RBV, ribavirin; SMV, simeprevir; DCV, daclatasvir; SVR, sustained virologic response.

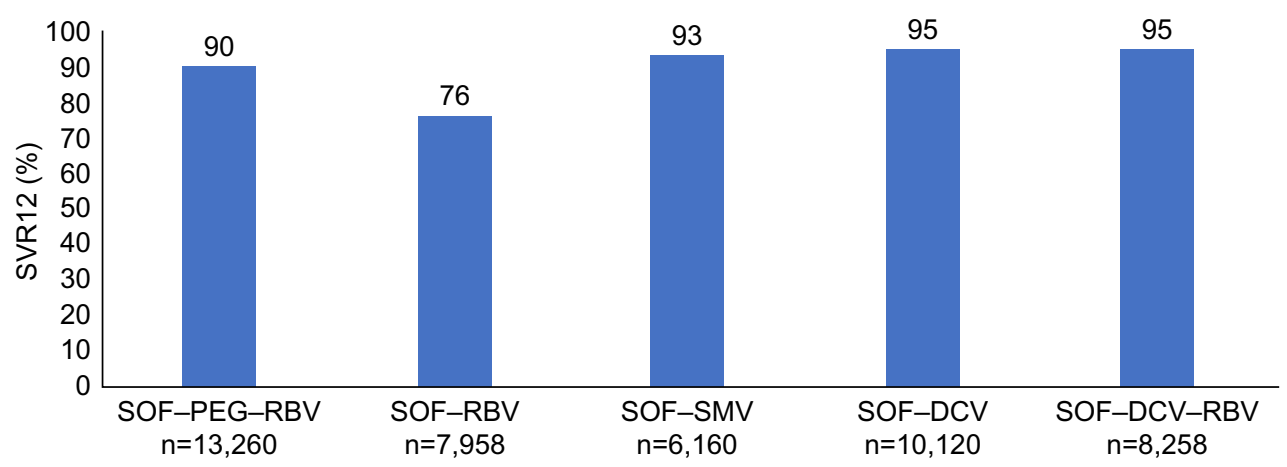

Figure 3 Real-life SVRI2 results with different DAA treatment regimens in the Egyptian national program.

Note: El Raziky et al and Doss et al. ${ }^{45,46}$

Abbreviations: SVR, sustained virologic response; DAA, direct-acting antivirals; SOF, sofosbuvir; PEG, pegylated interferon; RBV, ribavirin; SMV, simeprevir; DCV, daclatasvir. 


\section{Conclusion}

The large national treatment program to treat patients with $\mathrm{HCV}$ infection was feasible and manageable. Scaling up of the treatment program was possible with the availability of more medications, with more affordability through both allocating more resources and decreasing costs, with the decision to treat all stages of fibrosis and with removing the requirement of strict fibrosis assessment.

Each country's availability of resources, availability of medication and expected number of patients will determine the initial treatment and prioritization strategies. In the Egyptian program, rapid adaptation to changes in availability and modification of the guidelines were a key to the success in including and managing this huge number of patients in this short time. With limited resources and limited availability of drugs, choosing liver fibrosis as a priority parameter for mass treatment projects was the best recourse for national program in order to prioritize patients in whom therapy is urgently needed.

The treatment of hundreds of thousands of patients with $>90 \%$ SVR rates in a short time will hopefully lead to achieving the target of HCV disease control and eventual elimination in Egypt. How far will successful therapy change the epidemiology of the disease remains to be seen.

\section{Disclosure}

Imam Waked received grants/research supports or speaker's honoraria from Abbvie, Gilead Sciences, Janssen, Marcyrl, Mylan, Onxio, Pharco, and Roche. The authors report no other conflicts of interest in this work.

\section{References}

1. Blach S, Zeuzem S, Manns M, et al. Global prevalence and genotype distribution of hepatitis $C$ virus infection in 2015: a modelling study. Lancet Gastroenterol Hepatol. 2016;2(3):161-176.

2. Saeed AA, al-Admawi AM, al-Rasheed A, et al. Hepatitis C virus infection in Egyptian volunteer blood donors in Riyadh. Lancet. 1991;338(8764):459-460.

3. Strickland G. Liver disease in Egypt: hepatitis C superseded schistosomiasis as a result of iatrogenic and biological factors. Hepatology. 2006;43(5):915-922.

4. Elgharably A, Gomaa AI, Crossey MME, Norsworthy PJ, Waked I, Taylor-Robinson SD. Hepatitis C in Egypt - past, present, and future. Int J Gen Med. 2017;10:1-6.

5. Rao MR, Naficy AB, Darwish MA, et al. Further evidence for association of hepatitis $\mathrm{C}$ infection with parenteral schistosomiasis treatment in Egypt. BMC Infect Dis. 2002;2:29.

6. Frank C, Mohamed MK, Strickland GT, et al. The role of parenteral antischistosomal therapy in the spread of hepatitis $\mathrm{C}$ virus in Egypt. Lancet. 2000;355(9207):887-891.

7. Kamel MA, Ghaffar YA, Wasef MA, Wright M, Clark L, Miller FD. High HCV prevalence in Egyptian blood donors. Lancet. 1992;340(8816):427.
8. Mohamoud Y, Mumtaz G, Riome S, Miller D, Raddad L. The epidemiology of hepatitis $\mathrm{C}$ virus in Egypt: a systematic review and data synthesis. BMC Infect Dis. 2013;13:288.

9. Darwish MA, Raouf TA, Rushdy P, Constantine NT, Rao MR, Edelman R. Risk factors associated with a high seroprevalence of hepatitis $\mathrm{C}$ virus infection in Egyptian blood donors. Am J Trop Med Hyg. 1993;49(4):440-447.

10. Bassily S, Hyams KC, Fouad RA, Samaan MD, Hibbs RG. A high risk of hepatitis $\mathrm{C}$ infection among Egyptian blood donors: the role of parenteral drug abuse. Am J Trop Med Hyg. 1995;52(6):503-505.

11. Abdel-Aziz F, Habib M, Mohamed MK, et al. Hepatitis C virus (HCV) infection in a community in the Nile Delta: population description and HCV prevalence. Hepatology. 2000;32(1):111-115.

12. El-Zanaty F, Way A. Egypt Demographic and Health Survey 2008. Cairo: Ministry of Health, El-Zanaty and Associates, and Macro International; 2009:431.

13. Razavi H, Waked I, Sarrazin C, et al. The present and future disease burden of hepatitis $\mathrm{C}$ virus with today's treatment paradigm. $J$ Viral Hepat. 2014;21(suppl 1):34-59.

14. Waked I, Doss W, El-Sayed M, et al. The current and future disease burden of chronic hepatitis $\mathrm{C}$ virus infection in Egypt. Arab J Gastroenterol. 2014;15(2):45-52.

15. Ministry of Health and Population [Egypt], El-Zanaty and Associates [Egypt], ICF International. Egypt Health Issues Survey 2015. Cairo, Rockville, MD: Ministry of Health and Population, ICF International; 2015.

16. Kandeel A, Genedy M, El-Refai S, Funk A, Fontanet A, Talaat M. The prevalence of HCV infection in Egypt 2015: implications for future policy on prevention and treatment. Liver Int. 2017;37:45-53.

17. Westbrook RH, Dusheiko G. Natural history of hepatitis C. J Hepatol. 2014;61(1):S58-S68.

18. Sanyal AJ. The Institute of Medicine report on viral hepatitis: a call to action. Hepatology. 2010;51(3):727-728.

19. Alazawi W, Cunningham M, Dearden J, Foster GR. Systematic review: outcome of compensated cirrhosis due to chronic hepatitis $\mathrm{C}$ infection. Aliment Pharmacol Ther. 2010;32(3):344-355.

20. Eltabbakh M, Zaghla H, Abdel-Razek W, et al. Utility and cost effectiveness of screening for hepatocellular carcinoma in a resource limited setting. Med Oncol. 2015;32(4):432-437.

21. Maasoumy B, Wedemeyer H. Natural history of acute and chronic hepatitis C. Best Pract Res Clin Gastroenterol. 2012;26(4):401-412.

22. Lee M-H, Yang HI, Lu SN, et al; R.E.V.E.A.L.-HCV Study Group. Chronic hepatitis $\mathrm{C}$ virus infection increases mortality from hepatic and extrahepatic diseases: a community-based long-term prospective study. J Infect Dis. 2012;206(4):469-477.

23. van der Meer AJ, Veldt BJ, Feld JJ, et al. Association between sustained virological response and all-cause mortality among patients with chronic hepatitis C and advanced hepatic fibrosis. JAMA. 2012;308(24):2584-2593.

24. Adinolfi LE, Restivo L, Guerrera B, et al. Chronic HCV infection is a risk factor of ischemic stroke. Atherosclerosis. 2013;231(1):22-26.

25. Elhawary EI, Mahmoud GF, El-Daly MA, Mekky FA, Esmat GG, AbdelHamid M. Association of HCV with diabetes mellitus: an Egyptian case-control study. Virology. 2011;8(1):367.

26. White DL, Ratziu V, El-Serag HB. Hepatitis C infection and risk of diabetes: a systematic review and meta-analysis. $J$ Hepatol. 2008;49(5):831-844.

27. Soliman A, Boffetta P. Chapter 14: lymphoma and leukemia. In: Freedman LS, Edwards BK, Ries LAG, Young JL, editors. Cancer Incidence in Four Member Countries (Cyprus, Egypt, Israel, and Jordan) of the Middle East Cancer Consortium (MECC) Compared with US SEER. Bethesda, MD: National Cancer Institute; 2017. NIH Pub. No. 06-5873, 2006; 131-140. Available from: http://seer.cancer.gov/archive/publications/mecc/mecc_monograph.pdf. Accessed April 13, 2017.

28. Hsu YC, Lin JT, Ho HJ, et al. Antiviral treatment for hepatitis C virus infection is associated with improved renal and cardiovascular outcomes in diabetic patients. Hepatology. 2014;59(4):1293-1302. 
29. Ibrahim EM, Madian A. Impact of hepatitis $C$ on health-related quality of life in Egypt. J Am Sci. 2011;7(11):430-439.

30. Estes C, Abdel-Kareem M, Abdel-Razek W, et al. Economic burden of hepatitis C in Egypt: the future impact of highly effective therapies. Aliment Pharmacol Ther. 2015;42(6):696-706.

31. Shelbaya A, Kuznik A, Salem M, Mankola W, Sadik K. P1265: estimating the epidemiologic and economic impact of different treatment rates for hepatitis C virus (HCV) in Egypt. J Hepatol. 2015;62:S832-S833.

32. World Health Organization [webpage on the Internet]. Disability Adjusted Life Years (DALY). Available at: http://www.who.int/healthinfo/ global_burden_disease/metrics_daly/en. Accessed April 13, 2017.

33. Central Agency for Public Mobilization and Statistics, CAPMAS [webpage on the Internet]. Statistical Yearbook - National Accounts: Expenditure on GDP at Market 12/13 - 14/15. Available from: http:// www.capmas.gov.eg/Pages/StaticPages.aspx?page_id=5034. Accessed April 13, 2017.

34. American Diabetes Association. Economic costs of diabetes in the US in 2012. Diabetes Care. 2013;36(4):1033.

35. World Bank [webpage on the Internet]. Health Expenditure, Total (\% of GDP). Available from: http://data.worldbank.org/indicator/ SH.XPD.TOTL.ZS. Accessed April 13, 2017.

36. Wong JB, McQuillan GM, McHutchison JG, Poynard T. Estimating future hepatitis $\mathrm{C}$ morbidity, mortality, and costs in the United States. Am J Public Health. 2000;90(10):1562-1569.

37. Wedemeyer H, Duberg AS, Buti M, et al. Strategies to manage hepatitis C virus (HCV) disease burden. JViral Hepat. 2014;21(suppl 1):60-89.

38. Mankoula $\mathrm{W}$ [webpage on the Internet]. Estimating Economic and Epidemiological Burden of Hepatitis C in Egypt, 2015-2025. Available from: http://dar.aucegypt.edu/handle/10526/4590. Accessed January 18, 2016.

39. El-Akel W, El-Sayed MH, El Kassas M, et al. National treatment programme of hepatitis $\mathrm{C}$ in Egypt: hepatitis $\mathrm{C}$ virus model of care. $J$ Viral Hepat. 2017;24(4):262-267.
40. Doss W, Mohamed MK, Esmat G, et al. Egyptian National Control Strategy for Viral Hepatitis 2008-2012. Arab Republic of Egypt, Ministry of Health and Population, National Committee for the Control of Viral Hepatitis; 2008. Available from: http://www.hepnile.org/images/ stories/doc/NSP_10_April_2008_final2.pdf. Accessed December 10, 2016.

41. Donald GM [webpage on the Internet]. Curing Hepatitis $C$, in an Experiment the Size of Egypt. The New York Times; 2015. Available from: http://www.nytimes.com/2015/12/16/health/hepatitis-c-treatmentegypt.html. Accessed April 13, 2017.

42. AASLD [homepage on the Internet]. AASLD/IDSA Guidelines. Available from: http://www.hcvguidelines.org. Accessed December 10, 2016.

43. European Association for the Study of the Liver. EASL recommendations on treatment of hepatitis C 2016. J Hepatol. 2017;66(1): 153-194.

44. Doss W, Shiha G, Hassany M, et al. Sofosbuvir plus ribavirin for treating Egyptian patients with hepatitis C genotype 4. J Hepatol. 2015;63(3):581-585.

45. El Raziky M, Gamil M, Ashour MK, et al. Simeprevir plus sofosbuvir for 8 or 12 weeks in treatment-naïve and -experienced hepatitis $\mathrm{C}$ virus genotype 4 patients with or without cirrhosis. $J$ Viral Hepat. 2017;24(2):102-110.

46. Doss W, Esmat G, El-Serafy M, et al. Real-Life Results of Sofosbuvir Based Therapy for Egyptian Patients with Hepatitis $C$ and Advanced Fibrosis-Cirrhosis. Barcelona: EASL; 2016.

47. Central Agency for Public Mobilization and Statistics, CAPMAS. Estimates of Midyear Population by Age Groups. 2006-2012. Available from: http://www.capmas.gov.eg/Pages/Publications.aspx?page_ id $=5104 \&$ Year=16539. Accessed April 13, 2017.

48. Central Agency for Public Mobilization and Statistics, CAPMAS [webpage on the Internet]. Estimates of Midyear Population by Age Groups. 2006-2015. Available from: http://www.capmas.gov.eg/Pages/ StaticPages.aspx?page_id=5034. Accessed April 13, 2017.
Hepatic Medicine: Evidence and Research

\section{Publish your work in this journal}

Hepatic Medicine: Evidence and Research is an international, peerreviewed, open access journal covering all aspects of adult and pediatric hepatology in the clinic and laboratory including the following topics: Pathology, pathophysiology of hepatic disease; Investigation and treatment of hepatic disease; Pharmacology of drugs used for the treatment

\section{Dovepress}

of hepatic disease. Issues of patient safety and quality of care will also be considered. The manuscript management system is completely online and includes a very quick and fair peer-review system, which is all easy to use. Visit http://www.dovepress.com/testimonials.php to read real quotes from published authors. 